\title{
Stability and Change in Fertility Preferences Among Young Women in Malawi
}

By Christie Sennott and Sara Yeatman

Christie Sennott is a doctoral candidate in sociology at the University of Colorado,

Boulder, USA, and

Sara Yeatman is assistant professor in the Department of Health and Behavioral Sciences at the University of Colorado, Denver.

CONTEXT: Although studies have demonstrated change in fertility preferences over time, there is a lack of definitive knowledge about the level and direction of change among individuals, especially young and unmarried women. Furthermore, little is known about the factors associated with changes in fertility preferences over time.

METHOD: The analysis uses the first five waves of data from a longitudinal study of a random sample of women aged 15-25 in southern Malawi. The data were collected four months apart over an 18-month period, between June 2009 and December 2010. Multinomial logit regression models were used to calculate relative risk ratios and identify associations between four categories of life events - reproductive, relationship, health and economicand shifts in fertility timing preferences.

RESULTS: In each four-month period, more than half of the women reported changes in the desired timing of their next birth, and delays and accelerations in timing desires were common. Several life events, including having a child, entering a serious relationship and changes in household finances were associated with changes in the level and direction of fertility preference.

CONCLUSION: Shifts in fertility timing preferences often occur in response to changes in life circumstances. Understanding the reasons for these shifts may aid family planning providers in meeting women's contraceptive needs. International Perspectives on Sexual and Reproductive Health, 2012, 38(1):34-42, doi: 10.1363/3803412

Fertility preferences are important measures for forecasting fertility, calculating levels of unwanted or mistimed fertility and assessing unmet need for contraceptives. One of the assumptions underlying the use of fertility preferences for these objectives is that they are relatively stable over time. ${ }^{1}$ However, in Sub-Saharan Africa-where fertility, both desired and actual, remains comparatively high and childbearing patterns are increasingly heterogeneousfertility preferences are likely to be unstable.* Very little research has focused on how individuals' fertility timing desires change over time; however, there is evidence that other fertility preferences respond to changes in life circumstances. ${ }^{2,3}$ Indeed, researchers in the region have argued that even individuals who are committed to a particular family size may temporarily alter their fertility preferences in response to changes in economic or reproductive circumstances. ${ }^{2,3}$ In studies from Africa, fertility preferences reported in surveys are often tentative and malleable. ${ }^{2-6}$ Such flexibility may allow for change in fertility preferences, even over short time periods. Understanding how fertility timing preferences change over time is particularly useful, because the timing of births is likely to influence ul-

*The existence of heterogeneous childbearing patterns in the midst of high fertility suggests that social norms regarding fertility are in flux. Thus, women in such a context may have more flexibility in terms of the desired number or timing of future children. Additionally, women may face fewer negative social sanctions for varying their childbearing preferences (or patterns) than might be the case where fertility rates are low or where most women follow the same childbearing path. timate family size, perhaps even more so than individuals ideal number of children.

In fertility transition research, which has traditionally focused on aggregate measures of fertility preferences and their predictors, structural changes, such as economic development and societal improvements in education and health, are associated with changes in country-level fertility preferences. ${ }^{7-12}$ However, fertility preferences are characteristics of individuals and couples, not countries. Rarely have studies, particularly in Sub-Saharan Africa, examined how changes in life circumstances relate to an individual's fertility preferences.

The present study uses five waves of longitudinal data collected in rural Malawi in 2009-2010 to examine the stability of women's fertility preferences over time and the life events that are associated with delays or accelerations in the desired timing of the next birth.

\section{Charting Preferences over Time}

Fertility is highly valued in Sub-Saharan Africa, and the desire to stop childbearing is rare among younger women. Still, a woman may be reasonably certain that she wants to have another child, but she may be less sure about when she wants to have a child; equally, she may be more focused on whether now is the right time to have a child with a particular partner than on precisely how many children she plans to have over her lifetime. ${ }^{2}$ This suggests that women's fertility preferences may change over short time 
periods, which may be particularly true for young or lowerparity women, as they may experience more economic uncertainty and relationship instability. ${ }^{3,13-16}$

Studies in Africa have documented considerable change in individuals' fertility preferences over time. ${ }^{17-20}$ In two studies, one from Morocco and the other from Ghana, approximately two-thirds of women changed their family size preferences over two and three years, respectively. ${ }^{21,22}$ In another study from Ghana that used multiple waves of closely spaced data (approximately nine months apart), women changed their preference for wanting a child or for the desired timing of the next birth in more than one-third of the survey waves. ${ }^{23}$

Fertility preferences are related to several factors, including age, education, and marital and socioeconomic status. As life circumstances evolve, so too may fertility preferences. In Sub-Saharan Africa, women may alter their preferences because of relationship changes and the influence of their partner's preferences; ${ }^{21,24}$ child mortality; ${ }^{21,25}$ pregnancy or pregnancy complications; ${ }^{23}$ and changes in economic circumstances, employment or health. ${ }^{21,23,26}$

Most of the studies that have investigated change in fertility preferences over time both in Africa and in the West have used data points spaced at least one year apart, although many have used considerably longer periods. ${ }^{21,25,27,28}$ Multiple changes in preferences may occur over the years and are likely to be missed when there are long gaps between surveys, potentially leading researchers to overestimate the stability of preferences. In addition, long periods between surveys make it possible for a variety of changes to take place in respondents' lives, complicating efforts to isolate characteristics or events that could be associated with change. Shorter reference periods make it easier for researchers to measure changes in fertility preferences as they occur in tandem with other life events. Furthermore, shorter reference periods are particularly useful for capturing fluctuations in short-term fertility preferences, such as the desired timing of the next birth, which may be more sensitive to changing life circumstances.

The objective of this study is to examine the stability of and identify the factors associated with fertility timing preferences in a sample of young Malawian women. Our analysis first describes how the desired timing of the next birth changes across five closely spaced waves of data over 18 months. Next, we investigate how changes in relationships, reproductive experiences, health and economic circumstances relate to changes in the desired timing of the next birth.

\section{Context}

At six children per woman, Malawi's total fertility rate remains comparatively high. ${ }^{29}$ Average fertility varies by women's residence, education and other background characteristics, with education and wealth inversely related to fertility. ${ }^{29}$ Women living in rural areas have higher fertility than women in urban areas ( 6.4 vs. 4.2 births per woman, respectively). Nationally, the mean ideal family size among women aged $15-49$ is 4.1 . The fertility rate peaks between the ages of 20 and 24 for Malawian women, and the median age at first birth is 19 , a statistic that has remained relatively stable over time. ${ }^{29}$

As elsewhere in eastern Africa, HIV prevalence is high in Malawi-approximately $11 \%$ of Malawian adults are estimated to be HIV-positive. ${ }^{30}$ Knowing or suspecting that one is HIV-positive is associated with changes in fertility preferences in this context. ${ }^{31,32}$

\section{METHODS}

Data

Data for this study come from the first five waves of Tsogolo la Thanzi,* an ongoing longitudinal study of young women and their partners in southern Malawi. The survey waves are four months apart, and the data used here were collected between June 2009 and December 2010. The Tsogolo la Thanzi sample was drawn from a complete household listing in April 2009 of all individuals who lived within seven kilometers of Balaka, a town approximately 90 kilometers from the southern city of Blantyre. The sampling frame for Tsogolo la Thanzi included not only household members, but also people living in boarding schools and rest houses (motels used as residences, often for sex workers) within the catchment area. The Tsogolo la Thanzi sample was selected using a random number generator from the complete list of men and women aged 15-25. Ninety-six percent of eligible women were interviewed at baseline (Wave 1), and approximately $85 \%$ of these respondents were reinterviewed at Wave 5. Highly trained Malawian interviewers conducted interviews in Chichewa in private rooms at the Tsogolo la Thanzi research center. The current analysis is limited to the female Tsogolo la Thanzi sample.

\section{Unit of Analysis}

The unit of analysis for the study is a segment, defined as the period of time between two successive interviews. Women were not necessarily interviewed at every wavesome left the study and reentered at later waves. Thus, a woman who was interviewed at Wave 1, missed Wave 2, reentered the study at Wave 3, and was interviewed then and at Wave 4 would have contributed two segments: one between Waves 1 and 3 and one between Waves 3 and 4. The multivariate models contain 4,608 segments that measured change in fertility timing preferences. The vast majority of segments are one wave long; the majority of respondents contributed all four possible segments (82\%).

\section{Variables}

The dependent variable for our analysis is the desired timing of the next birth. At each interview, respondents were asked how long they would like to wait before having their next child. Responses included: as soon as possible; less

*Tsogolo la Thanzi is a research project designed by Jenny Trinitapoli and Sara Yeatman. See http://projects.pop.psu.edu/tlt for more information. 
TABLE 1: Percentage distribution of women aged 15-25 who provided baseline data for Tsogolo Ia Thanzi, according to selected characteristics, Malawi, 2009-2010

\begin{tabular}{|c|c|}
\hline Characteristic & $\begin{array}{l}\text { \% or mean } \\
(\mathrm{N}=1,254)\end{array}$ \\
\hline \multicolumn{2}{|l|}{ MEANS } \\
\hline Age & $19.4(3.3)$ \\
\hline $\begin{array}{l}\text { Household } \\
\text { socioeconomic index }\end{array}$ & $2.7(1.7)$ \\
\hline \multicolumn{2}{|l|}{ PERCENTAGE DISTRIBUTIONS } \\
\hline \multicolumn{2}{|l|}{ Marital status } \\
\hline No partner & 43.9 \\
\hline Married & 38.2 \\
\hline Serious nonmarital partner & 17.9 \\
\hline \multicolumn{2}{|l|}{ Education } \\
\hline No education & 1.8 \\
\hline Primary & 43.1 \\
\hline Some secondary & 43.8 \\
\hline Completed secondary & 11.3 \\
\hline \multicolumn{2}{|l|}{ No. of living children } \\
\hline 0 & 51.3 \\
\hline 1 & 25.2 \\
\hline 2 & 17.0 \\
\hline$\geq 3$ & 6.5 \\
\hline \multicolumn{2}{|l|}{ Desired timing of next birth } \\
\hline$<2$ yrs. & 14.4 \\
\hline $2-3 \mathrm{yrs}$ & 16.0 \\
\hline 3-4 yrs. & 17.1 \\
\hline $4-5$ yrs. & 13.4 \\
\hline$\geq 5$ yrs. & 31.7 \\
\hline Don't want a(nother) child & 7.4 \\
\hline Total & 100.0 \\
\hline
\end{tabular}

Notes: Numbers in parentheses are standard deviations.

than two years; two to three years; three to four years; four to five years; five or more years; and don't want a(nother) child. Four percent (67) of respondents gave a nonnumeric response ("don't know" or "whenever/no preference") at a minimum of one wave and were excluded from the analytic sample. We grouped respondents who reported that they wanted a child as soon as possible with those who reported wanting a child in less than two years, because both categories reflect a desire for pregnancy in the near term. A change in the desired timing of the next birth was measured at each wave and coded as no change (reference category), a desire to delay or to accelerate the timing of the next birth.

The key independent variables in the explanatory models are life events that had occurred since a respondent's last interview. We measured the four categories of life events-reproductive, relationship, health and economicat each wave after the first interview. We included only life events that were experienced by at least $5 \%$ of the sample between their first and second interviews. * All items were coded dichotomously.

- Reproductive events. Women who experience a pregnancy or birth are likely to change the desired timing of their next birth and may also reconsider their overall family size goals, in response to unanticipated life changes associated with the pregnancy or birth. ${ }^{26}$ Tsogolo la Thanzi data in- clude current pregnancy status and a biomarker for pregnancy at each interview. A woman was considered to have had a new pregnancy between interviews if she reported one since the previous interview, or if she had not reported a pregnancy at the previous interview but subsequently had tested positive for pregnancy (i.e., a likely unknown pregnancy). Because a new pregnancy is highly likely to alter the desired timing of the next birth, all models of timing apart from the baseline model include a control for new pregnancy. Respondents were considered to have had a new birth if they reported having had a child between interviews.

- Relationship events. Both beginning a new relationship and exiting a relationship might influence fertility preferences. Respondents were considered to have gained a partner if they had married or become seriously involved with a nonmarital partner. They were considered to have lost a partner if they had divorced, become widowed, or separated from a spouse or serious nonmarital partner. We accounted for the possibility that a woman might have both gained and lost a partner between interviews. Women were also asked whether they had heard rumors that their partner was unfaithful since the last interview. This question was designed to capture doubts about a partner's fidelity. (Infidelity is a common cause of divorce in Malawi. ${ }^{33}$ ) This variable was intended to measure relationship instability that might be related to a change in fertility preferences.

- Health events. Dramatic changes in health may influence fertility preferences. In Malawi, where HIV prevalence is high, changes in the health of a woman or her partner may suggest an HIV infection, prompting a revision of fertility preferences. Several studies have documented this tendency-to alter fertility preferences whether HIV is actually diagnosed or only suspected because of a downturn in health-in African countries such as Malawi, ${ }^{31,32}$ Zimbabwe $^{34}$ and Tanzania, ${ }^{35}$ where HIV is common. Of course, health changes unrelated to HIV also might be associated with shifting preferences. For example, stints of poor health-whether related to a reproductive event ${ }^{4,5}$ or to an illness-may encourage a woman to delay her next pregnancy until she feels well enough to carry it to term. Health events measured in this study include experiencing a decline in health, losing weight (a symptom of HIV infection), ${ }^{36}$ or having a spouse or partner who has become ill.

-Economic events. Events that change one's economic circumstances might alter plans for future childbearing. For example, losing a job could prompt postponement of pregnancy to allow time for a household to recover financially before adding another member. Conversely, a spouse beginning a new job could accelerate a woman's childbearing plans. Frequent changes in fertility preferences may also reflect the economic uncertainty that is common in developing societies ${ }^{2,3,6}$ such as Malawi, where employment may be sporadic or scarce. To measure economic change,

*Fewer than $5 \%$ of the sample had a new birth during the first two seg ments because the sample was restricted to women not knowingly pregnant at their baseline interview. 
our models include whether a respondent had moved to a better house, her spouse or partner had gotten a good or better job, or her household had experienced a food shortage since the last interview.

\section{Baseline Controls: Social and Demographic Variables}

Several social and demographic variables, measured at baseline and associated with fertility preferences, are included as controls in all multivariate models. We use a three-category variable for relationship status: single (reference category), married and serious nonmarital partnership. Education is categorized as no education (reference category), primary, some secondary education or completed secondary schooling. Age is coded continuously, and we include a quadratic age or "age-squared" term, to account for nonlinear age effects. Socioeconomic status is captured through an index of household goods. Respondents were asked to identify which of the following nine working items they owned: bed with mattress, television, radio, landline or mobile phone, refrigerator, bicycle, motorcycle, animal-drawn cart and car or truck. The index is created by summing the total number of items reported by each respondent. We include a variable for the number of living children. Fewer than 1\% of the sample had more than three children, so we combine those women into one category.

\section{Sample Selection}

All female respondents who were not knowingly pregnant at baseline and participated in at least one additional interview qualified for inclusion in the analytic sample. Fewer than $1 \%$ of respondents were not interviewed at Wave 1 and instead completed a baseline interview at Wave 2 . Respondents were excluded if they were missing data on the desired timing of their next birth at any wave at which they were interviewed (2); answered "don't know" (14); or stated "no preference/whenever" (45). Excluded respondents, compared with those in the analytic sample, were, on average, one year older; they had, on average, one year less of education and one less working household good on the socioeconomic index; and they were less likely to be single. The final sample contained 1,254 Malawian women who were aged $15-25$ at the baseline interview (83\% of the female respondents who completed a baseline interview).

\section{Analytic Strategy}

We begin by describing the extent of change in fertility timing preferences across four, four-month segments. Next, we use multivariate models to examine associations between selected characteristics and life events, and change in timing preferences. We use multinomial logit regression analyses, calculating relative risk ratios to separately compare the likelihood of changes (accelerations and delays) in the desired timing of next birth with the likelihood of no change. We control for the baseline fertility timing preference in all models. Because some women reported in nonconsecutive waves, segments may be different lengths;
TABLE 2: Percentage of women who experienced life events across four segments of the Tsogolo la Thanzi study, Malawi, 2009-2010

\begin{tabular}{lcccc} 
Event & $\begin{array}{c}\text { Segment 1 } \\
(\mathrm{N}=1,254)\end{array}$ & $\begin{array}{l}\text { Segment 2 } \\
(\mathrm{N}=1,195)\end{array}$ & $\begin{array}{l}\text { Segment 3 } \\
(\mathrm{N}=1,128)\end{array}$ & $\begin{array}{l}\text { Segment 4 } \\
(\mathrm{N}=1,031)\end{array}$ \\
\hline Reproductive & & & & \\
New pregnancy & 7.3 & 8.6 & 8.1 & 6.8 \\
New birth & 0.6 & 3.9 & 6.7 & 8.2 \\
& & & & \\
Relationship & & & & 3.0 \\
Rumors about partner's fidelity & 6.9 & 5.3 & 4.2 & 5.6 \\
Lost a partner & 5.3 & 6.4 & 6.7 & 10.7 \\
Gained a partner & 11.4 & 8.6 & 9.2 & \\
& & & & \\
Health & & & & \\
Decline in health & 5.9 & 4.9 & 6.1 & 5.2 \\
Lost weight & 6.1 & 7.5 & 5.4 & 4.5 \\
Spouse illness & 6.7 & 7.0 & 5.3 & 3.8 \\
& & & & \\
Economic & 13.2 & 12.2 & 8.1 & 12.7 \\
Better house & 8.5 & 6.0 & 4.7 & 4.4 \\
Spouse better job & 20.4 & 19.3 & 9.6 & 9.9 \\
Food shortage & & & &
\end{tabular}

Notes: $\mathrm{N}=$ number of segments. A segment is defined as the period of time between two successive interviews.

therefore, we include an indicator in each model to account for the length of each segment. In each model, we also include an indicator of the wave in which the segment ends to account for respondents having been interviewed over multiple waves and for potential seasonal variation.

\section{RESULTS}

At the baseline interview, the mean age of the respondents was 19.4 years (Table 1 ). More than half $(56 \%)$ of the respondents were either married or in a serious nonmarital relationship. The majority had some education (98\%), and more than half (55\%) had at least some secondary schooling. The women in this sample had relatively few children: half $(51 \%)$ had none and one-quarter had just one child

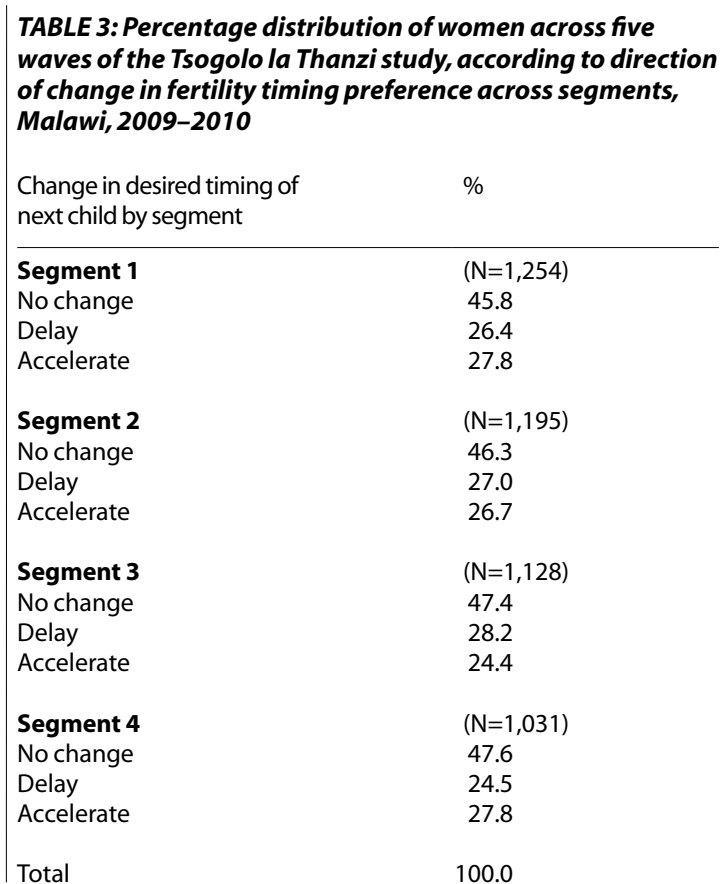


TABLE 4. Relative risk ratios from multinomial logit regression analyses examining associations between selected characteristics and life events, and change in desired timing of next birth, Tsogolo la Thanzi, Malawi, 2009-2010

\begin{tabular}{|c|c|c|c|c|c|c|c|c|c|c|c|c|}
\hline \multirow[t]{2}{*}{ Characteristic } & \multicolumn{2}{|l|}{ Model 1} & \multicolumn{2}{|l|}{ Model 2} & \multicolumn{2}{|l|}{ Model 3} & \multicolumn{2}{|l|}{ Model 4} & \multicolumn{2}{|l|}{ Model 5} & \multicolumn{2}{|l|}{ Model 6} \\
\hline & Delay & Accelerate & Delay & Accelerate & Delay & Accelerate & Delay & Accelerate & Delay & Accelerate & Delay & Accelerate \\
\hline \multicolumn{13}{|l|}{$\begin{array}{l}\text { DEMOGRAPHIC } \\
\text { Relationship status }\end{array}$} \\
\hline No partner (ref) & 1.00 & 1.00 & 1.00 & 1.00 & 1.00 & 1.00 & 1.00 & 1.00 & 1.00 & 1.00 & 1.00 & 1.00 \\
\hline Married & 0.90 & 0.86 & 0.83 & 0.85 & 0.85 & 0.99 & 0.84 & 0.85 & $0.82 \dagger$ & 0.85 & 0.84 & 0.97 \\
\hline Serious partner & 1.20 & 1.11 & 1.10 & 1.10 & 1.07 & 1.15 & 1.11 & 1.11 & 1.09 & 1.10 & 1.06 & 1.14 \\
\hline \multicolumn{13}{|l|}{ Education } \\
\hline No education (ref) & 1.00 & 1.00 & 1.00 & 1.00 & 1.00 & 1.00 & 1.00 & 1.00 & 1.00 & 1.00 & 1.00 & 1.00 \\
\hline Primary & 0.82 & 0.70 & 0.86 & 0.71 & 0.87 & 0.73 & 0.85 & 0.70 & 0.86 & 0.71 & 0.88 & 0.73 \\
\hline Some secondary & 0.94 & 0.67 & 1.03 & 0.68 & 1.05 & 0.70 & 1.02 & 0.67 & 1.03 & 0.69 & 1.05 & 0.70 \\
\hline Completed secondary & 0.96 & 0.71 & 1.08 & 0.73 & 1.09 & 0.74 & 1.07 & 0.71 & 1.07 & 0.73 & 1.10 & 0.73 \\
\hline Age & $2.48^{* * *}$ & $3.82^{* * *}$ & $2.45^{* * *}$ & $3.80^{* * *}$ & $2.42^{* * *}$ & $3.66^{* * *}$ & $2.45^{* * *}$ & $3.82^{* * *}$ & $2.41^{* * *}$ & $3.70^{* * *}$ & $2.37^{* * *}$ & $3.53^{* * *}$ \\
\hline Quadratic age term & $0.98^{* * *}$ & $0.97^{* * *}$ & $0.98^{* * *}$ & $0.97^{* * *}$ & $0.98^{* * *}$ & $0.97^{* * *}$ & $0.98^{* * *}$ & $0.97^{* * *}$ & $0.98^{* * *}$ & $0.97^{* * *}$ & $0.98^{* * *}$ & $0.97^{* * *}$ \\
\hline Socioeconomic status & $0.94^{*}$ & $0.96+$ & $0.95+$ & $0.96+$ & $0.95^{*}$ & $0.96+$ & $0.95^{*}$ & $0.96+$ & $0.95^{*}$ & 0.97 & $0.95^{*}$ & 0.97 \\
\hline $\begin{array}{l}\text { Baseline timing } \\
\text { preference }\end{array}$ & $0.83^{* * *}$ & $1.05^{*}$ & $0.84^{* * *}$ & $1.06^{*}$ & $0.84^{* * *}$ & $1.06^{*}$ & $0.84^{* * *}$ & $1.05^{*}$ & $0.84^{* * *}$ & $1.06^{*}$ & $0.85^{* * *}$ & $1.07^{* *}$ \\
\hline No. of living children & $1.25^{* *}$ & 1.07 & $1.30 * * *$ & 1.07 & $1.29 * *$ & 1.05 & $1.30^{* * *}$ & 1.07 & $1.30^{* *}$ & 1.05 & $1.29^{* *}$ & 1.04 \\
\hline Length of segment & 0.99 & 0.96 & 0.95 & 0.96 & 0.94 & 0.95 & 0.95 & 0.96 & 0.91 & 0.88 & 0.91 & 0.88 \\
\hline \multicolumn{13}{|l|}{ Wave ending segment } \\
\hline Wave 2 (ref) & 1.00 & 1.00 & 1.00 & 1.00 & 1.00 & 1.00 & 1.00 & 1.00 & 1.00 & 1.00 & 1.00 & 1.00 \\
\hline Wave 3 & 1.00 & 0.92 & 0.98 & 0.91 & 0.98 & 0.94 & 0.98 & 0.92 & 0.99 & 0.94 & 0.99 & 0.94 \\
\hline Wave 4 & 1.03 & 0.87 & 1.01 & 0.85 & 1.03 & 0.88 & 1.02 & 0.87 & 1.04 & 0.92 & 1.03 & 0.91 \\
\hline Wave 5 & 0.88 & 0.95 & 0.88 & 0.93 & 0.89 & 0.95 & 0.89 & 0.96 & 0.90 & 1.00 & 0.90 & 0.98 \\
\hline \multicolumn{13}{|l|}{ LIFE EVENTS } \\
\hline \multicolumn{13}{|l|}{ Reproductive } \\
\hline New pregnancy & na & na & $5.27^{* * *}$ & 1.12 & $5.18^{* * *}$ & 0.99 & $5.25^{* * *}$ & 1.11 & $5.23^{* * *}$ & 1.08 & $5.22^{* * *}$ & 0.98 \\
\hline New birth & na & na & 1.15 & 1.32 & & & & & & & 1.12 & 1.29 \\
\hline \multicolumn{13}{|l|}{ Relationship } \\
\hline Rumor about partner & na & na & na & na & 1.19 & 0.90 & na & na & na & na & 1.19 & 0.84 \\
\hline Lost a partner & na & na & na & na & 1.26 & 1.03 & na & na & na & na & 1.28 & 1.03 \\
\hline Gained a partner & na & na & na & na & 1.17 & $1.98^{* * *}$ & na & na & na & na & 1.14 & $1.93^{* * *}$ \\
\hline \multicolumn{13}{|l|}{ Health } \\
\hline Decline in health & na & na & na & na & na & na & 0.93 & 1.00 & na & na & 0.92 & 0.98 \\
\hline Lost weight & na & na & na & na & na & na & 1.13 & 1.30 & na & na & 1.11 & 1.25 \\
\hline Spouse/partner illness & na & na & na & na & na & na & 0.98 & 1.01 & na & na & 0.97 & 0.95 \\
\hline \multicolumn{13}{|l|}{ Economic } \\
\hline Better house & na & na & na & na & na & na & na & na & 1.10 & $1.37^{* *}$ & 1.08 & $1.31 *$ \\
\hline Spouse/partner better job & na & na & na & na & na & na & na & na & $1.53^{*}$ & $1.52^{* *}$ & $1.53^{*}$ & $1.45^{*}$ \\
\hline Food shortage & na & na & na & na & na & na & na & na & 0.97 & $1.31^{*}$ & 0.96 & $1.30^{*}$ \\
\hline
\end{tabular}

${ }^{*} \mathrm{p}<.05 .{ }^{* *} \mathrm{p}<.01 .{ }^{* * *} \mathrm{p}<.001 . \mathrm{tp}<.10$. Notes: $\mathrm{N}=$ number of segments $=4,608$. A segment is defined as the period of time between two successive interviews. For socioeconomic status, baseline timing preference and number of living children, each unit increase (one additional item on the socioeconomic goods index, wanting to have the next birth later or having one more living child) indicates a corresponding increase/decrease in the likelihood of an acceleration/delay in timing preference, when other variables are held constant. For age, a one unit increase indi-

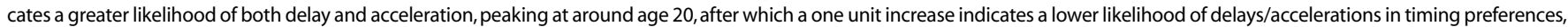

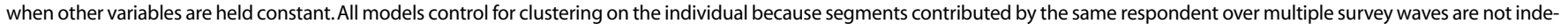
pendent. na $=$ not applicable.

Comparatively few women wanted to have a child within two years (14\%); the majority reported wanting to wait two or more years (78\%), including 32\% who wanted to wait five or more years. Seven percent of the sample reported wanting no more children.

Most life events were experienced by fewer than 10\% of the women at each segment (Table 2, page 37). The most commonly experienced events were gaining a partner (9$11 \%)$, moving to a better house (8-13\%) and experiencing a food shortage (10-20\%). The frequency with which both positive (better house) and negative (food shortage) economic events were reported over such short periods of time illustrates the somewhat rapid economic change and high level of economic uncertainty that individuals in Malawi experience.

\section{Change in Fertility Preferences}

More than half of the women changed their fertility timing preference over each segment (Table 3, page 37). A majority of the respondents (83\%) reported at least one 
change in timing preference over the course of the study (not shown). Although we would expect some movement in timing preference during the course of a year and a half, this high level of change suggests that fertility timing preferences may be particularly responsive to everyday events. Directionally, there is no clear pattern-the proportions of changes that represent delays and accelerations in the desired timing of the next birth vary by segment.

\section{Life Events Associated with Changes in Timing Preferences}

Age, socioeconomic status, baseline timing preference and number of living children were associated with shifts in timing preferences (Table 4). Women whose age fell in the middle of the sample's age range-around age 20were more likely than younger and older women to report changes (both delays and accelerations) in timing preferences (not shown). Women from higher socioeconomic status households had more stable timing preferences than poorer women. Women with a higher baseline timing preference were less likely to desire to delay and more likely to desire to accelerate their next birth, suggesting some regression toward the mean. However, women with more children were more likely to desire to delay the timing of their next birth. This finding is largely explained by these women deciding not to have any more children (not shown).

A new pregnancy was positively associated with a desire to postpone the next birth. A new birth, however, was not associated with changes in fertility timing preferences. When relationship events were considered, gaining a partner was associated with a desire to accelerate the timing of the next birth. None of the health events included in the analyses was related to changes in the desired timing of the next birth. Several of the economic events were associated with changes in timing preferences. A better house was associated with a preference to accelerate the timing of the next birth; a spouse or partner gaining a good or better job was positively associated with changes in both directions (accelerations and delays); and experiencing a food shortage was associated with a desire to accelerate the next birth. The inclusion of these economic life events rendered the relationship between baseline socioeconomic status and the likelihood of accelerating the next birth insignificant. Finally, after controlling for all types of events, none of the associations disappeared, and all retained their direction.

\section{DISCUSSION}

Our results show considerable change in fertility timing preferences in a sample of young Malawian women interviewed up to five times over an 18-month period. During each segment, more than half of the respondents changed timing preferences; and more than $80 \%$ of respondents reported at least one change over the full 18 months.

We found several significant relationships between events in the women's lives and changes in their fertility timing preferences. Unsurprisingly, a new pregnancy was the life event most strongly associated with a change in timing preference: a desired postponement of the next birth. Women's fertility timing preferences have been found to be strong predictors of whether or when they become pregnant in the future. ${ }^{37} \mathrm{~A}$ change in fertility timing preference in response to a new pregnancy may therefore represent the successful fulfillment of a previously stated timing preference, especially if a woman reported wanting a child as soon as possible. Upon further investigation, two-thirds of the women who experienced a new pregnancy reported at their next interview that they would like to have their next child later than they had previously stated (not shown). Nonetheless, one-third of women who experienced a new pregnancy either reported no change in their fertility timing preference or said that they would like to have their next child sooner than they had previously stated (not shown). Women may revise timing preferences at the advent of an unexpected pregnancy and desire to have another child sooner because normative birth spacing in Malawi is two to three years. ${ }^{38}$ Thus, despite her previous desire to postpone childbearing, once a woman has started bearing children she may prefer to have them in relatively close succession.

Regarding relationship events, the only variable that was associated with changes in timing preferences was gaining a partner, which was linked to a desire to accelerate the pace of childbearing. This association is likely related to the social norm in Malawi that couples have a child within the first year of marriage. In a society with comparatively little nonmarital fertility, ${ }^{39}$ these findings likely reflect most young women's experiences.

We found a number of relationships-some surprisingbetween changes in economic circumstances and fertility timing preferences. Women who had moved into a better house were more likely to report a desire to accelerate the timing of their next birth. This finding remained significant even after controlling for a new relationship, including marriage. We interpret moving to a better house as an act of settling down and a marker of improved economic conditions that may motivate a woman or couple to want to have a child. We also found that a spouse or partner having acquired a good or better job was associated with changes in timing preferences in both directions. At first glance, this result was confusing: We had expected improved economic circumstances to be associated only with a desire to accelerate the next birth. However, in Malawi, where migration is common, getting a new job may require a partner to move, which might delay subsequent childbearing. Because of the relationship between a spouse's or partner's employment and changes in fertility timing preferences, we also considered whether a woman's work would affect her desired timing for the next birth. Yet, at each segment (the cutoff for inclusion in the study), fewer than $5 \%$ of women had gained a good or better job, and we did not find a significant relationship between this event and changes in timing preferences (not shown).

Finally, we found a positive association between having experienced a food shortage and wanting to have the next 
child sooner. A food shortage was one of the most common life events in all segments, affecting one-third (31\%) of women at some point during the 18-month study period (not shown). A food shortage might indicate a worsening economic situation for a household, which may then motivate a woman to have a child sooner, before the situation deteriorated further. Additionally, there may be a link between hunger and sex for young women in this context. Research from Brazil ${ }^{40}$ has demonstrated that in times of hunger, sex may serve both practical and pleasurable functions. Sex may lead to an increase in resources for women through a relationship with a man or the birth of a child; it also may provide compensatory gratification (i.e., pleasure to make up for the loss they experience during a food shortage). The potential of a birth to strengthen social and economic support for young women also has been documented in South Africa. ${ }^{41}$

This study has a number of limitations. First, the Tsogolo la Thanzi sample comprises young women early in their reproductive years-a group that may have been particularly likely to experience changes in fertility timing preferences. Therefore, the extent of change observed here may have been higher than that among older, married or higher parity women. Second, although shorter intervals are useful for producing estimates that better approximate the true level of change, they may not capture the longerterm effects of some life events. Finally, the extent to which many of the short-term changes in fertility preferences identified here resulted from measurement error or unpredictable fluctuation, rather than real change, is unclear. The finding of some regression toward the mean suggests that some correction did occur.

Our results suggest that fluctuations in fertility preferences are often in response to changes in life circumstances, but not always in easily predictable ways. This lends support to the sequential model of fertility decisionmaking, ${ }^{26}$ and builds on the qualitative findings of Agadjanian, ${ }^{3}$ Johnson-Hanks ${ }^{2}$ and others. Future research that uses a wider selection of variables as well as qualitative data may capture different types of life events and individual-level mechanisms that are linked to changes in fertility timing preference.

Our findings are relevant to family planning experts and providers who are interested in gauging when (and how) young women's fertility preferences may change. When a woman's fertility preferences shift, her needs for contraceptive services and methods also may change. By demonstrating the frequency with which young women's fertility timing preferences might change, even over a relatively short period of time, and the characteristics and noteworthy life events that might be associated with those changes, our findings may help health care providers meet young women's evolving reproductive needs so that they can achieve their reproductive goals.

Several areas would benefit from further research. Although scholars are investigating ways in which HIV may affect fertility preferences and behaviors, ${ }^{31,42-44}$ we still know little about how non-HIV-related health changes affect fertility desires. Our study found that women's fertility timing preferences were sensitive to economic changes but that some of the relationships did not lend themselves to easy interpretation. Given the considerable demographic literature and interest in the relationship between economic development and fertility change, more research is needed to understand how economics and fertility are related at the individual level. Finally, fertility decisions are not made in a vacuum. Future research should investigate the potential influence of partners and family on young women's fertility preference formation and change.

\section{REFERENCES}

1. Casterline JB and El-Zeini LO, The estimation of unwanted fertility, Demography, 2007, 44(4):729-745.

2. Johnson-Hanks J, Natural intentions: fertility decline in the African Demographic and Health Surveys, American Journal of Sociology, 2007, 112(4): 1008-1043

3. Agadjanian V, Fraught with ambivalence: reproductive intentions and contraceptive choices in a Sub-Saharan fertility transition, Population Research and Policy Review, 2005, 24(6):617-645.

4. Bledsoe C, Fatoumatta B and Hill AG, Reproductive mishaps and western contraception: an African challenge to fertility theory, Population and Development Review, 1998, 24(1):15-57.

5. Bledsoe C, Contingent Lives: Fertility, Time and Aging in West Africa, Chicago: University of Chicago Press, 2002.

6. Johnson-Hanks J, When the future decides: uncertainty and intentional action in contemporary Cameroon, Current Anthropology, 2005, 46(3):363-385

7. Caldwell JC, Toward a restatement of demographic transition theory, Population and Development Review, 1976, 2(3/4):321-366.

8. Caldwell J, Mass education as a determinant of the timing of fertility decline, Population and Development Review, 1980, 6(2):223-255.

9. Cleland J, Marital fertility decline in developing countries: theories and evidence, in: Cleland J and Hobcraft J, eds., Reproductive Change in Developing Countries: Insights from the World Fertility Survey, Oxford: Oxford University Press, 1985, pp. 223-252.

10. Heer DM, Economic development and fertility, Demography, 1966, 3(2):423-444.

11. Kirk D and Pillet B, Fertility levels, trends, and differentials in Sub-Saharan Africa in the 1980s and 1990s, Studies in Family Planning, 1998, 29(1):1-22.

12. Weinberger MB, The relationship between women's education and fertility: selected findings from the World Fertility Surveys, International Family Planning Perspectives, 1987, 13(2):35-46.

13. Hayford SR, The evolution of fertility expectations over the life course, Demography, 2009, 46(4):765-783.

14. Morgan SP and Rackin H, The correspondence between fertility intentions and behavior in the United States, Population and Development Review, 2010, 36(1): 91-118.

15. Rocca $\mathrm{CH}$ et al., Pregnancy intentions and teenage pregnancy among Latinas: a mediation analysis, Perspectives on Sexual and Reproductive Health, 2010, 42(3):186-196.

16. Zabin LS, Ambivalent feelings about parenthood may lead to inconsistent contraceptive use-and pregnancy, Family Planning Perspectives, 1999, 31(5):250-251.

17. Bankole A and Singh S, Couples' fertility and contraceptive decision-making in developing countries: hearing the man's voice, International Family Planning Perspectives, 1998, 24(1):15-24.

18. Gipson JD and Hindin MJ, 'Marriage means having children and forming your family, so what is the need of discussion? 
Communication and negotiation of childbearing preferences among Bangladeshi couples, Culture, Health \& Sexuality, 2007, 9(2): 185-198.

19. Lloyd CB and Montgomery MR, The consequences of unintended fertility for investments in children: conceptual and methodological issues, Policy Research Division Working Paper, New York: Population Council, 1996, No. 89.

20. Montgomery MR and Cohen B, From Death to Birth: Mortality Decline and Reproductive Change, Washington, DC: National Academies of Sciences, 1998

21. Bankole A and Westoff CF, The consistency and validity of reproductive attitudes: evidence from Morocco, Journal of Biosocial Science, 1998, 30(4):439-455

22. Debpuur $\mathrm{C}$ and Bawah AA, Are reproductive preferences stable? Evidence from rural northern Ghana, Genus, 2002, LVIII(2):63-89.

23. Kodzi IA, Casterline JB and Aglobitse P, The time dynamics of individual fertility preferences among rural Ghanaian women, Studies in Family Planning, 2010, 41(1):45-54.

24. Dodoo FN, Men matter: additive and interactive gendered preferences and reproductive behavior in Kenya, Demography, 1998, 35(2):229-242.

25. Joyce T, Kaestner R and Korenman S, The stability of pregnancy intentions and pregnancy-related maternal behaviors, Maternal and Child Health Journal, 2000, 4(3):171-178.

26. Udry JR, Do couples make fertility plans one birth at a time? Demography, 1983, 20(2):117-128.

27. Schoen $\mathrm{R}$ et al., Do fertility intentions affect fertility behavior? Journal of Marriage and Family, 1999, 61(3):790-799.

28. Westoff CF and Ryder NB, The predictive validity of reproductive intentions, Demography, 1977, 14(4):431-453.

29. National Statistical Office (NSO) and ORC Macro, Malawi Demographic and Health Survey 2004, Calverton, MD, USA: NSO and ORC Macro, 2005

30. Joint United Nations Programme on HIV/AIDS (UNAIDS), HIV and AIDS Estimates (2009), 2009, <http://www.unaids.org/en/ regionscountries/countries/malawi/>, accessed Jan. 18, 2011.

31. Yeatman SE, The impact of HIV status and perceived status on fertility desires in rural Malawi, AIDS and Behavior, 2009, 13(1 Suppl.):S12-S19.

32. Yeatman SE, HIV infection and fertility preferences in rural Malawi, Studies in Family Planning, 2009, 40(4):261-276.

33. Reniers G, Divorce and remarriage in rural Malawi, Demographic Research, Special Collections, 2003, Vol. 1, pp. 175-206.

34. Grieser $\mathrm{M}$ et al., Reproductive decision making and the HIV/ AIDS epidemic in Zimbabwe, Journal of Southern African Studies, 2001, 27(2):225-243.

35. Ainsworth M, Filmer D and Semali I, The impact of AIDS mortality on individual fertility: evidence from Tanzania, in: Montgomery $\mathrm{M}$ and Cohen B, eds., From Death to Birth, Washington, DC: National Academy Press, 1998, pp. 138-180.

36. Watkins SC, Navigating the AIDS epidemic in rural Malawi, Population and Development Review, 2004, 30(4):673-705.

37. Kodzi IA, Johnson DR and Casterline JB, Examining the predictive value of fertility preferences among Ghanaian women, Demographic Research, 2010, 22(30):965-984.

38. Rafalimanana $\mathrm{H}$ and Westoff CF, Potential effects on fertility and child health and survival of birth-spacing preferences in sub-Saharan Africa, Studies in Family Planning, 2000, 31(2):99-110.

39. Singh S, Adolescent childbearing in developing countries: a global review, Studies in Family Planning, 1998, 29(2):117-136.

40. Scheper-Hughes N, Death Without Weeping: The Violence of Everyday Life in Brazil, Berkeley, CA, USA: University of California Press, 1992.
41. Madhavan S, Early childbearing and kin connectivity in rural South Africa, International Journal of Sociology of the Family, 2010, 36(2):139-157.

42. Setel PW, The effects of HIV and AIDS on fertility in East and Central Africa, Health Transition Review, 1995, 5(Suppl):179-189.

43. Zaba B and Gregson S, Measuring the impact of HIV on fertility in Africa, AIDS, 1998, 12(1 Suppl.):S41-S50

44. Cooper D et al., "Life is still going on": reproductive intentions among HIV-positive women and men in South Africa, Social Science E Medicine, 2007, 65(2):274-283

\section{RESUMEN}

Contexto: Aunque algunos estudios han demostrado el cambio en las preferencias sobre fecundidad a través del tiempo, hay una falta de conocimientos definitivos sobre el nivel y dirección del cambio entre las mujeres, especialmente las mujeres jóvenes y solteras. Además, se sabe poco sobre los factores asociados con cambios en las preferencias de fecundidad a través del tiempo.

Método: El análisis utiliza las primeras cinco olas de datos de un estudio longitudinal con base en una muestra aleatoria de mujeres en edades de 15-25 en el sur de Malaui. Los datos fueron recolectados con un espaciamiento de cuatro meses a lo largo de un período de 18 meses, entre junio de 2009 y diciembre de 2010. Se usaron modelos de regresión logit multinomial para calcular las razones de riesgo relativo e identificar las asociaciones entre cuatro categorias de acontecimientos vitales y los cambios en las preferencias respecto al momento apropiado para tener hijos. Las cuatro categorías abarcan los eventos reproductivos, económicos, de formación de pareja, y de salud. Resultados: En cada periodo de cuatro meses, más de la mitad de las mujeres reportaron cambios en el momento deseado para el nacimiento de su siguiente hijo; y los retrasos y apresuramientos en los deseos del momento apropiado para tener otro hijo resultaron ser comunes. Varios acontecimientos vitales, incluidos un nacimiento, la formación de pareja y cambios en las finanzas familiares, se asociaron con cambios en las preferencias reproductivas.

Conclusión: Los cambios en los deseos del momento apropiado para tener otro hijo con frecuencia ocurren en respuesta a cambios en las circunstancias de la vida. Comprender las razones que expliquen estos cambios puede ayudar a que los prestadores de servicios de planificación familiar satisfagan las necesidades de anticoncepción de las mujeres.

\section{RÉSUMÉ}

Contexte: Si la recherche a démontré l'évolution des préférences de fécondité au fil du temps, la connaissance n'est guère définitive quant au niveau et à la direction du changement, parmi les femmes jeunes et célibataires surtout. Les facteurs associés aux changements des préférences de fécondité au fil du temps sont du reste peu connus.

Méthode: L'analyse repose sur les cinq premières vagues de données d'une étude longitudinale d'un échantillon aléatoire de femmes âgées de 15 à 25 ans dans le sud du Malawi. Les données ont été collectées à intervalles de quatre mois sur une période de 18 mois, entre juin 2009 et décembre 2010. Des modèles de régression logit multinomiale servent à calculer les 
rapports de risque relatif et à identifier les associations entre quatre catégories d'événements de vie (génésique, relation, santé et économie) et la variation des préférences temporelles de fécondité.

Resultats: Durant chaque période de quatre mois, plus de la moitié des femmes ont déclaré un changement du moment désiré de leur prochaine naissance; les reports et accélérations des désirs exprimés se sont révélés courants. Plusieurs événements de vie, tels que la naissance d'un enfant, l'établissement d'une relation sérieuse et les fluctuations des finances du ménage, sont associés aux changements de niveau et de direction de la préférence de fécondité.

Conclusion: La variation des préférences temporelles de fécondité survient souvent en réponse aux changements des circonstances de la vie. Comprendre les raisons de cette variation pourrait aider les prestataires de la planification familiale à répondre aux besoins de contraception des femmes.

\section{Acknowledgments}

The authors are grateful to the National Institute of Child Health and Human Development, which funded the Tsogolo la Thanzi research project and provided some salary support for the authors through NICHD R01-HD058366.

\section{Acknowledgment to Reviewers}

The editors wish to express their appreciation to the following reviewers for their assistance in evaluating material for International Perspectives on Sexual and Reproductive Health in 2011:

$\begin{array}{ll}\text { Carla AbouZahr } & \text { Catherine d'Arcangues } \\ \text { Ramesh Adhikari } & \text { Michele R. Decker } \\ \text { Lukasz Aleksandrowicz } & \text { Mai Do } \\ \text { Amina Alio } & \text { Anibal Faundes } \\ \text { Keera Allendorf } & \text { William A. Fisher } \\ \text { Akinrinola Bankole } & \text { Sharon Fonn } \\ \text { Alka Barua } & \text { Karen G. Foreit } \\ \text { Joy Noel Baumgartner } & \text { Angel Foster } \\ \text { Ann E. Biddlecom } & \text { Michel Garenne } \\ \text { Deborah L. Billings } & \text { Bina Gubhaju } \\ \text { Bruce K. Caldwell } & \text { Sarah Hayford } \\ \text { Jacquelyn Campbell } & \text { Douglas Huber } \\ \text { John B. Casterline } & \text { Sunita Kishor }\end{array}$

G. Anil Kumar

Lisa Langhaug

Susan Lee-Rife

Monica Magadi

Paulina Makinwa-Adebusoye

Sanyu Mojola

Nico Nagelkerke

Y. Abisola Noah

Saroj Pachauri

Tia M. Palermo

Anne Paxton

Elena Prada

Heidi W. Reynolds
Hamisu Salihu

Vinit Sharma

Tara M. Sullivan

Shyam Thapa

John W. Townsend

Janet Turan

Jennifer A. Wagman

Wenjuan Wang

Ina Warriner

Mary Beth Weinberger

Zhenzhen Zheng

Eliya Zulu 